\title{
Tax Evasion and the Optimal Tax Treatment of Foreign-Source Income
}

\author{
Xiwen Fan ${ }^{\mathrm{a}^{*}}$ and John Douglas Wilson ${ }^{\mathrm{b} \dagger}$
}

${ }^{a}$ Radian Asset Assurance Inc.

${ }^{b}$ Michigan State University

\begin{abstract}
This paper models a capital-exporting country that encounters difficulties in taxing foreignsource income, due to tax evasion problems. The paper compares the country's optimal effective tax rates on the income from capital invested at home and abroad (including penalties levied on detected tax evaders). It finds that tax evasion abroad does not provide a justification for a relatively low effective rate on foreign-source income. Under a variety of circumstances, foreignsource income should actually be taxed at a relatively high effective rate, regardless of the severity of tax evasion problems abroad. However, tax evasion abroad does tend to reduce the optimal taxation of capital income both at home and abroad.
\end{abstract}

JEL Classification: $\mathrm{H} 21, \mathrm{H} 25, \mathrm{H} 26, \mathrm{H} 87$

Keywords: tax evasion, optimal taxation, capital tax, capital mobility

\section{Introduction}

With the increasing international mobility of capital, it is becoming increasingly difficult to collect taxes on capital. Theory alone tells us that a small country, facing an internationally-determined return on capital, will choose not to collect taxes on only the capital income earned within its borders - a "source-based tax" - if it has sufficient access to domestic commodity taxes. For example, Bucovetsky and Wilson (1991) prove that a small country will tax only wage income, despite the distortion to labor supply

Director, Global Structured Products, Radian Asset Assurance. The views expressed by Dr. Fan are exclusively his own and do not represent the views of Radian Asset Assurance Inc. or any of its affiliates (including, without limitation, its ultimate parent, Radian Group Inc.).

Correspondence address: Professor John D. Wilson, Department of Economics, Marshall-Adams Hall, Michigan State University, East Lansing, MI 48824 USA. Tel: 1-517-432-3116. Fax: 1-517-432-1068. E-mail: wilsonjd@msu.edu. 
decisions. ${ }^{1}$ Gordon (1986) shows that if a country could tax its residents' worldwide income regardless of where it was obtained, then this "residence-based tax" would also be employed. ${ }^{2}$ But a country's ability to tax foreign-source income is typically quite limited. Noncompliance appears to be widespread, and legal tax avoidance schemes are readily available. ${ }^{3}$ Even if governments choose to tax capital income at source, the existence of international tax havens create income-shifting activities that allow investors to avoid the tax. ${ }^{4}$

Despite the prediction that countries should choose not to tax mobile capital, corporate taxes have remained a significant source of government revenue in recent years. See, in particular, the evidence discussed by Hines (2007) and Auerbach, Devereux and Simpson (2007). There are many possible explanations for this finding. Hines (2007) argues that countries are becoming increasingly adept at distinguishing between mobile and immobile capital, allowing them to continue to tax relatively immobile capital at relatively high rates. Smart and Qing (2006) argue that through the use of foreign tax havens, mobile capital is effectively taxed less than immobile capital, even if their statutory tax rates are similar. Wilson (2007) emphasizes departures from the assumptions needed for the Diamond-Mirrlees (1971) theorem on aggregate production efficiency, which lies behind the conclusion that a country's capital imports or exports should not be distorted by source-based taxation. In particular, Diamond and Mirrlees assume there are no untaxed profits, and they ignore the administrative costs involved in collecting taxes. If capital income were exempted from taxation, then taxpayers would have an incentive to shift the income they report to the tax authority away from wage income and towards capital income, creating the need for the government to engage in costly monitoring activities to limit such income-shifting activities. Gordon and MacKie-Mason (1995) formally develop this argument.

To focus on the use of source-based taxes, this theoretical literature models the difficulties of taxing foreign-source income by simply assuming that such taxes are not possible. But despite such difficulties, there exists some scope for collecting these taxes, and many countries do attempt to tax the income generated by their residents' foreign direct investment. ${ }^{5}$ Davies (2004) describes the growing importance of tax treaties among governments attempting to tax foreign direct investment, and explains that an important use of these treaties is to prevent tax evasion through the exchange of information between governments. Reviewing the literature on information-sharing and international taxation, Keen and Ligthart (2006) describe cases where informationsharing can arise voluntarily as the outcome of a non-cooperative game between countries.

\footnotetext{
${ }^{1}$ Bucovetsky and Wilson also show that the equilibrium tax on capital is positive when the country possesses market power on world capital markets.

${ }^{2}$ For a review of the theoretical literature on international taxation, see Gresik (2001).

${ }^{3}$ For foreign direct investment, legal and illegal schemes may be intertwined through the bending of transfer-pricing rules to reduce tax burdens.

${ }^{4}$ See Slemrod and Wilson (2007) and the references therein.

${ }^{5}$ Such taxation typically involves the use of tax credits for taxes paid to host governments, and a few countries use tax deductions. We discuss the use of tax credits as one of the extensions of our basic model.
} 
Thus, rather than simply assume that foreign-source income cannot be taxed, the preferable route would be to model the difficulties in collecting this tax, and endogenously derive the relative use of source- and residence-based taxes. Otherwise, the deck seems to be unfairly stacked against any taxation of internationally-mobile capital as part of an optimal tax system. We take this approach in the current paper.

Some rough intuition might suggest no surprises here. If attempts to collect taxes on a resident's foreign-source income generate socially-costly tax evasion and avoidance activities, then the government may seek to lower these social costs by levying relatively low effective tax rates on this foreign-source income. For the case of optimal commodity taxation, for example, Cremer and Gahvari (1993) provide a similar argument, and conclude that "the expected tax rate in the... market which is subject to tax evasion will be less than in the market without tax evasion" (p. 271). ${ }^{6}$ This "expected rate" (which corresponds to our "effective rate") is based on tax evasion and avoidance activities, detection probabilities, and penalty rates. Applying this reasoning to the issue of international taxation, we might similarly reason that taxes on foreign-source income should be low relative to taxes on income earned at home, due to the difficulties involved in collecting taxes on foreign-source income.

In contrast to this reasoning, our paper demonstrates that for a capital-exporting country facing tax evasion abroad, foreign-source capital income should be taxed at a higher effective rate than domestic capital income, assuming there also exist tax evasion problems at home. In this sense, the optimal tax system seems closer to a residencebased system than to a source-based system, even when it is difficult to tax foreignsource income. Our results provide some justification for the taxation of internationallymobile capital.

Thus, one theme of our paper is that in an open economy, the intuition that effective tax rates should be set relatively low where tax evasion is high is of limited value. The essential insight behind our results is that the international mobility of capital causes tax evasion problems abroad which get translated into lower optimal tax rates abroad and at home, and tax evasion problems at home then lead to an even lower effective tax rate at home. Intuitively, tax evasion abroad enables investors at home to escape taxation by moving their investments abroad. In fact, tax rates on both domestic and foreign-source income go to zero as the severity of tax evasion abroad rises to the point where taxing capital abroad becomes impossible; i.e. the Bucovetsky-Wilson result of no sourcebased taxation is reached as a limiting case of the model. Thus, to the extent that taxing foreign-source income becomes impossible, there remains the problem of justifying any taxation of foreign-source income.

The following section presents the basic model, and section 3 then compares the optimal tax rates on capital income at home and abroad. Sections 4 and 5 consider a number of extensions and alternative specifications of the model, arguing that the case for relatively large tax rates on foreign-source income does extend beyond the specific assumptions of our main model. Section 6 concludes the paper.

\footnotetext{
${ }^{6}$ The literature on tax evasion is reviewed by Slemrod and Yitzhaki (2002).
} 


\section{The Model}

We consider a world economy consisting of a capital-exporting "home country" and the rest of the world. A representative consumer, who divides an exogenous endowment, $I$, between current consumption and savings, inhabits the home country. ${ }^{7}$ The economy lasts for two periods, so savings are used to help pay for second-period consumption. Savings are allocated between investment at home and capital exports, denoted $K$ and $B$, respectively. In the second period, domestic firms produce output by combining their capital with labor provided by the consumer, and capital exports earn an exogenous return, $R$. We initially ignore taxes levied by foreign governments but then show how our analysis extends to include their presence.

We model tax evasion as occurring at the firm level. The representative consumer purchases shares in a large number of domestic firms, which then decide how to divide the consumer's savings between investments at home and abroad. By holding a fully diversified portfolio, the consumer avoids the potential risks associated with tax evasion by firms. Specifically, some firms are caught evading taxes and others are not, but the consumer earns an (almost) certain income on the diversified portfolio. While the assumption of tax evasion by firms motivates the absence of risk aversion, our framework can be interpreted more generally as one where risk aversion is not a factor, either because expenditures on evasion activities yield certain outcomes or because taxpayers are risk neutral. ${ }^{8}$ This concentration on the risk-neutral case eliminates considerations involving the optimal taxation of risky assets as a possible explanation for high tax rates on foreign-source income. Section 5 discusses how our results extend to the case where risk-averse investors also directly evade taxes on portfolio investments abroad.

We next describe the consumer's behavior, and then we turn to firm behavior and the government's welfare maximization problem.

\subsection{The Consumer's Problem}

The consumer maximizes utility subject to a lifetime budget constraint, requiring that the present value of consumption equal the present value of income:

$$
\begin{aligned}
& \text { (P.1) } \begin{array}{l}
\operatorname{Max} u\left(c^{1}, c^{2}, L\right) \\
c^{1}, c^{2}, L
\end{array} \\
& \text { s.t. } c^{1}+\frac{1}{q} c^{2}=I+\frac{1}{q} \omega L
\end{aligned}
$$

\footnotetext{
${ }^{7}$ The arguments given in Propositions 1 and 2 extend directly to a many-consumer economy, where a poll tax or subsidy is available but distortionary taxes are employed for income distribution reasons.

${ }^{8}$ In fact, tax evasion in our model can be interpreted more broadly to encompass both legal and illegal activities to reduce taxes, including those activities that require significant costs to reduce taxes by certain amounts. Blumenthal and Slemrod (1995) present evidence that the compliance costs associated with taxes on foreign-source income are much higher than those associated with domestic income.
} 
where $c^{i}$ is consumption in period $i(i=1,2), L$ is the labor supply, $I$ is the initial endowment of income, $q$ is one plus the after-tax return on savings (as specified below), and $\omega$ is the after-tax wage. The consumer's utility may also depend on public goods, but they will be treated as fixed throughout the analysis, so we may suppress them as separate arguments in the utility function.

It will be algebraically convenient to rewrite (1) in terms of future values:

$$
q c^{1}+\mathrm{c}^{2}-\omega L=q I \equiv M
$$

where $M$ is the future value of lump-sum income. With this notation, the solution to the consumer's problem yields an indirect utility function, $v(q, \omega, M)$, consumption functions, $c^{i}(q, \omega, M)$ for period $i$, and a labor supply function, $L(q, \omega, M)$.

\subsection{The Firm's Problem}

The home country contains a large but fixed number of competitive firms. Each of these firms obtains funds from the representative consumer for investment at home and abroad, and uses a constant-returns-to-scale production technology to produce a single output at home from labor and capital. We depict the aggregate behavior of firms by positing a representative firm with a production function, $F(K, L)$, relating the country's total output to the total amount of capital and labor employed there. This firm then chooses $K, L$, and $B$ to maximize profits.

To motivate the existence of a tax evasion problem in this model, the beforetax return on investment abroad, $R$, may be regarded as the expected value of a random variable that is i.i.d. across the individual firms. Firms observe this variable after committing to their investment plans, but tax evasion is possible because the government observes these variables only through random audits. Similarly, although firms must possess ex ante identical technologies for domestic production (since only the most efficient firms can survive in a competitive equilibrium), we may allow for random ex post differences due to technological uncertainty. Assuming no uncertainty at the aggregate level, $F(K, L)$ represents both expected and actual output. With the representative consumer holding a fully diversified portfolio, the appropriate objective for individual firms is to maximize expected profits, and this implies the maximization of aggregate profits for the economy.

Since constant returns to scale prevail in domestic production, the equilibrium capital-labor ratio is the solution to the problem of maximizing domestic profits per unit of labor:

$$
\underset{k}{\operatorname{Max}} F(k, 1)-r k-w
$$

where $r$ and $w$ are the before-tax returns on capital and labor in the home country. The tax system and tax evasion activities indirectly enter this problem through their impacts on the before-tax returns, as described below. In particular, $r$ must rise to compensate investors for the costs of evading domestic taxes. 
This problem defines $k$ as a decreasing function of $r: k=k(r) ; k^{\prime}(r)<0$. The total amount of domestic capital is then:

$$
K=k(r) L(q, \omega, M)
$$

and the requirement that equilibrium profits equal zero defines the following "factor-price frontier":

$$
w(r)=F(k(r), 1)-r k(r) ; \quad d w / d r=-k(r)
$$

The home government levies taxes on the income from labor and capital, and it uses the revenue to finance the exogenous level of public expenditures. We shall allow for tax evasion on capital income earned both at home and abroad, but the case where evasion occurs only abroad will be highlighted, since this case captures the idea that tax evasion on foreign-source income is especially widespread. In section 4 , we also allow taxes on labor income to be evaded.

Tax evasion at home and abroad is modeled in the same way, using a "reduced-form" model that captures the essential features of tax evasion for our study. A fully-specified evasion model that has these features is presented in the Appendix. To begin, let $T$ denote the tax rate on foreign-source income. The after-tax return on this income would then be $R(1-T)$ in the absence of tax evasion. However, the firm is able to spend real resources to lower the "effective tax rate" to some level, $T^{e}$, less than $T$. This effective rate may be interpreted as the expectation of a random tax rate, conditional on the audit policies and the penalties levied on the evaded income that is detected. The rate $T$ will sometimes be referred to as the "statutory rate," to distinguish it from $T^{e}$. But our interpretation of $T$ is that it would be the effective tax rate if there were no tax evasion. The penalties and activities undertaken to detect tax evasion (including their costs) are treated as fixed throughout the analysis, allowing us to concentrate on the suboptimization problem of choosing the tax rates that maximize the representative consumer's welfare. ${ }^{9}$ The effective tax rate is assumed to be increasing in $T$ but decreasing in the resources, $G$, spent on evading taxes per dollar of income (see the Appendix for the derivation of such a function):

$$
T^{e}=T^{e}(T, G) ; \quad \partial T^{e} / \partial T>0 ; \quad \partial T^{e} / \partial G<0
$$

The after-tax return on foreign-source income, calculated net of evasion costs, is $R(1-G)\left(1-T^{e}\right)$, and the firm's objective is clearly to maximize $(1-G)\left(1-T^{e}\right)$. Note our assumption that evasion costs are tax deductible in the calculation of taxable income. The basic idea here is that real resources are used to evade taxes (e.g. accountants, lawyers, less efficient production techniques), and the government is unable to

\footnotetext{
${ }^{9}$ For the tax evasion model presented in the Appendix, the optimal audit rate can be investigated by introducing a cost function for auditing. Cremer and Gahvari (1993) conduct this type of analysis for the case of optimal commodity taxation. However, the current model is not suitable for investigating the optimal penalty rate, since the assumption of risk-neutrality implies that the government could costlessly control tax evasion by increasing the penalty rate without bound.
} 
distinguish between these resources and those used in productive activities. This assumption simplifies the exposition, because the difference in ad valorem tax rates on income earned at home and abroad has the same sign as the difference in unit tax rates on capital at home and abroad, implying that we do not need to distinguish between the two types of rates in the statements of our results. But the implications of our results for unit tax rates and, hence, investment incentives, would continue to hold if evasion costs were not treated as tax deductible.

Since $T$ represents a parameter for the firm's tax evasion problem, the solution is a function of $T: G=G(T)$. There is a strong presumption that a rise in $T$ should increase $G$, since the expected taxes saved from failing to report another dollar of income should rise with $T$. The model in the Appendix has this property, but we will not need to restrict our analysis to it. It is important, however, that evasion activities in this model exhibit a certain type of "constant-returns". Specifically, the effective-tax-rate function, $T e(T, G)$, does not include capital exports $B$ as an argument. Alternatives are discussed in section 4 .

Tax policy and evasion at home are represented by lower case letters. Thus, $t^{e}=t^{e}(t, g)$, and the resulting evasion-cost function is $g=g(t)$. Some of our main results will depend on the assumption that $d g / d t \geq 0$, which again seems reasonable.

For an equilibrium division of investments between home and abroad, the after-tax returns on capital must be the same in both locations, taking into account evasion costs:

$$
R(1-G)(1-T e)=r(1-g)\left(1-t^{e}\right)
$$

Throughout this paper, (6) is referred to as the "arbitrage condition".

Observe that the arbitrage condition determines an equilibrium relation between the before-tax return at home, $r$, and the tax rates $T$ and $t$ :

$$
r=r(T, t) ; \quad \partial r / \partial T<0 ; \quad \partial r / \partial t>0
$$

where the derivatives follow from assumption (5) and the corresponding assumption for the taxation of domestic capital income. ${ }^{10}$ With taxes then determining $q$ and $\omega$ as specified below, the equilibrium $r$ can be used in (3) to determine domestic capital $K$. The difference between the total supply of capital and $K$ is then capital exports:

$$
B=I-c^{1}(q, \omega, M)-k(r) L(q, \omega, M)
$$

\subsection{The Government's Problem}

The government's problem consists of choosing taxes to maximize the value of the indirect utility function, $v(q, \omega, M)$, subject to a government budget constraint. To formally state the problem, consider first the determination of $q$. Under free capital mobility, the after-tax return on investment abroad, $R(1-G)\left(1-T^{e}\right)$, represents the marginal return on the representative consumer's savings. Hence, this return determines

\footnotetext{
${ }^{10}$ By the envelope theorem, the marginal impact of $\mathrm{T}$ on $R(1-G)\left(1-T^{e}\right)$ equals $-R(\partial T e / \partial T)<0$.
} 
the price of second-period consumption in the representative consumer's utilitymaximization problem:

$$
\frac{1}{q}=\frac{1}{1+R(1-G)\left(1-T^{e}\right)}
$$

Under the small country assumption, the country faces a fixed $R$, determined on the world capital market. Since $G$ and $T^{e}$ are functions of $T$, (9) defines $q$ as a function of $T$ alone: $q=q(T)$.

For the government budget constraint, we require that taxes be sufficient to finance the government's required expenditures, denoted $E$ :

$$
E \leq\left[(w(r)-\omega)+\operatorname{te}^{e}(1-g) k(r)\right] L(q, \omega M)+T^{e} R(1-G) B
$$

Substituting from (8) for capital exports $B$, we may rewrite (10) as follows:

$$
\begin{aligned}
& E \leq\left\{[w(r)-\omega]+\left[\operatorname{ter}(1-g)-T^{e} R(1-G)\right] k(r)\right\} L(q, \omega, M) \\
& +T^{e} R(1-G)\left[I-C^{1}(q, \omega, M)\right]
\end{aligned}
$$

After substituting from arbitrage condition (6) to rewrite (11), we have the final form of the maximization problem:

$$
\begin{aligned}
& \operatorname{Max} \quad v(q, \omega, M) \\
& \omega, t, T \\
& \text { s. } t . \quad E \leq\{[w(r)-\omega]+[r(1-g)-R(1-G)] k(r)\} L(q, \omega, M) \\
& +T^{e} R(1-G)\left[I-c^{1}(q, \omega, M)\right]
\end{aligned}
$$

where $r=r(T, t)$ and $q=q(T)$, as defined above. For convenience, we are using the aftertax wage as a control variable, in place of the tax rate on labor. ${ }^{11}$

In the absence of tax evasion, it is theoretically possible for the optimal $T$ to be negative in some cases, depending on the properties of the savings and labor supply functions. But at zero or negative tax rates, tax evasion is not a problem. To concentrate on the impact of tax evasion on relative tax rates, we shall assume in the text that it is optimal to collect some taxes on savings.

\section{The Optimal Tax System}

We now prove and discuss the main proposition of this paper:

Proposition 1. If tax evasion occurs only abroad, then $T^{e}=t$ and, therefore, $T>t$. If taxes on domestic capital income are evaded, with $g>0$ and $d g / d t \geq 0$, then $T^{e}>t^{e}$.

\footnotetext{
${ }^{11}$ Because the tax rates on capital determine evasion costs, it is not useful to follow the common practice of replacing these tax rates with consumer prices in the statement of the optimal tax problem.
} 
Proof. Since $t$ does not appear in the government's objective function, the first-order condition for $t$ is obtained by differentiating the government budget constraint, given by (12):

$$
[r(1-g)-R(1-G)] k^{\prime}(r) \frac{\partial r}{\partial t} L-\frac{\partial(r g)}{\partial t} K=0
$$

where use is made of the derivative, $w^{\prime}(r)=-k$, to cancel terms. We have previously observed that $\partial r / \partial t>0$ and $k^{\prime}(r)<0$. Using these inequalities, we conclude from (13) that $R(1-G)=r(1-g)$ in the absence of tax evasion at home, and $R(1-G)>r(1-g)$ if $g>0$ and $d g / d t \geq 0$. The arbitrage condition, given by (6), then confirms the claims about $T^{e}$ and $t^{e}$ in the proposition. Since tax evasion lowers $T^{e}$ below $T$, we will always have $T>t$ if there is tax evasion abroad but not at home. Q.E.D.

Equation (13) provides the basic intuition behind Proposition 1. Consider first the case where there is no domestic tax evasion. Suppose that we start with a tax system under which $T^{e}=t^{e}$, in which case capital is allocated efficiently so that its before-tax return, calculated net of evasion costs, is equalized across countries (i.e. the first of the two terms in (13) equals zero). If we now lower $t$, there will be a movement of capital from abroad to home, but this movement will have no first-order efficiency effects. Although total tax evasion will fall abroad, this benefit is offset by the shortfall of $r$ from $R$. With no domestic tax evasion, the reduction in $t$ has no other marginal costs or benefits. Thus, there is no reason to deviate from the efficient allocation of capital, so $T^{e}$ $=t^{e}$ is optimal.

If, however, firms respond to the lower $t$ by choosing to incur lower evasion costs per unit of capital at home $($ i.e. $-\partial(r g) / \partial t<0)$, then there is a first-order welfare gain. Hence it is optimal to reduce $t$. As $t$ declines, $t^{e}$ falls below $T^{e}$, causing $r(1-g)$ to fall below $R(1$ $-G)$. In other words, capital exports become inefficiently small. The optimal $t$ is found where a marginal reduction in $t$ produces a benefit in the form of lower evasion costs at home that just offsets the efficiency loss from the further reduction in capital exports. Note that we cannot simply repeat this argument with a reduction in $T$. Reducing $t$ has no impact on the after-tax return on savings, which is determined abroad. Instead, $r$ falls and $w$ rises so that individuals receive the same return both abroad and at home. In contrast, reducing $T$ does lower the after-tax return, so the optimal $T$ is determined by considerations involving how much savings should be taxed relative to labor.

To summarize, it is never optimal to tax domestic capital income at a higher effective rate than the effective rate on capital income earned abroad, and this conclusion holds regardless of how the costs of tax evasion differ between domestic and foreign-source income. In this sense, the optimal taxation of capital can never be said to "approximate" source-based taxation by taxing foreign-source income relatively lightly, even when tax evasion abroad is a serious problem. Turning to the statutory tax rates, it is possible for $T$ to fall short of $t$ without violating Proposition 1. However, if we continue to interpret the model as one in which tax evasion abroad is the more important problem, then $T$ will again exceed $t$.

It may seem puzzling that $T^{e}$ cannot lie below $t^{e}$, regardless of the severity of tax evasion abroad. The puzzle is resolved by observing that the proposition tells us only about the value of $T^{e}$ relative to $t^{e}$, not the absolute value of $T^{e}$. As tax evasion abroad 
becomes more severe, we can expect the optimal taxes on capital income both abroad and at home to fall. In other words, tax evasion abroad is translated via capital mobility into low tax rates on capital income at home, even if evasion at home is not a problem. In the limit, the taxation of capital income at home disappears as taxing capital income abroad becomes impossible. This brings us back to the Bucovetsky-Wilson result: if only source-based taxes are available, then they should not be used.

Additional insight into the influence of foreign tax evasion on taxes at home and abroad is obtained by using the first-order conditions for $T$ and the tax on labor income. These conditions, which are derived in the Appendix, can be combined into the following rule for an optimal tax system:

$$
\frac{\beta\left(-C_{\omega}^{1 s}\right)+T^{e} R\left(-C_{q}^{1 s}\right)}{I-c^{1}}=\frac{\beta L_{\omega}^{s}+T^{e} R L_{q}^{s}}{L}-\frac{B}{I-c^{1}}\left(\frac{d G / d T}{\partial T^{e} / \partial T}\right) \frac{1}{1-G^{\prime}}
$$

where subscripts denote partial derivatives, the partial derivative, $\partial T^{e} / \partial T$, indicates that $G$ is held fixed, the superscript " $s$ " indicates compensated ("Slutsky") demand and supply functions, and

$$
\beta=[w(r)-\omega]-w^{\prime}(r)\left[\operatorname{ter}(1-g)-T^{e} R(1-G)\right]
$$

i.e. $\beta$ measures the reduction in the after-tax wage caused by the tax system, including both the direct effect of the labor tax and the first-order effect of capital taxes on the before-tax wage. This rule differs from the Ramsey Rule, which would require that the tax system reduce the compensated demands for savings and labor by approximately the same percentage amounts (using first-order approximations). Instead, the rule tells us that the percentage reduction in savings should fall short of the percentage reduction in the labor supply by a positive amount, given by the second of the two terms on the right side of (14). This term is positively related to the marginal increase in evasion costs from an increase in the effective tax rate, and it may therefore be viewed as reflecting the severity of the tax evasion problem abroad. ${ }^{12}$ Thus (14) suggests that tax evasion abroad reduces the tax burden on savings, relative to labor. Only $T^{e}$ enters the tax rule, rather than $t^{e}$, because it is $T^{e}$ that determines the effective marginal tax on savings. But as $T^{e}$ falls in response to greater tax evasion abroad, $t^{e}$ will fall to maintain the discrepancy described by the first-order condition for $t$, (13). Hence, tax evasion abroad induces lower tax rates at home.

If we assume zero cross elasticities and no income effects, then (14) becomes a variant of the familiar inverse-elasticity rule:

$$
\frac{T^{e} R}{q} \varepsilon^{S}=\frac{\beta}{w} \varepsilon^{L}-\frac{B}{I-c^{1}}\left(\frac{d G / d T}{\partial T^{e} / \partial T}\right) \frac{1}{1-G}
$$

\footnotetext{
${ }^{12}$ In terms of the model described in the Appendix, a relevant measure of this severity is the elasticity of evaded income with respect to the tax rate, $\mu=(d A / d T)(T / A)$. Noting that $G(T)=G^{*}(A(T))$ and $\partial T^{e} / \partial T=T^{e} / T$, we have $\left.(d G / d T) / \partial T^{e} / \partial T\right)=G^{*}\left(A / T^{e}\right) \mu$. Thus, if we raise this evasion elasticity by rotating the firm's "evasion-supply curve", $\mathrm{A}(\mathrm{T})$, around its current equilibrium for the given $\mathrm{T}$ (which can be done by reducing the second derivative of $\left.\mathrm{G}^{*}(\mathrm{~A})\right)$, then we increase the marginal-evasion-cost term in (14).
} 
where $\varepsilon^{s}$ and $\varepsilon^{L}$ are the savings and labor supply elasticities. Given these elasticities, foreign tax evasion is clearly seen to reduce the taxation of savings relative to labor, and this reduction occurs both at home and abroad to maintain the discrepancy in tax rates identified by Proposition 1.

\section{Labor Taxation}

The previous section has described how optimal taxes on capital income abroad remain relatively high, even in the presence of severe tax evasion problems. In contrast, this section demonstrates how evasion in one market leads to relatively high optimal tax rates in another market. Specifically, we show that the evasion of taxes on labor income tends to raise the optimal expected tax rate on capital income at home relative to abroad. However, this finding does not appear to be sufficient to reverse Proposition 1, given reasonable assumptions about the relative importance of this new source of evasion.

We stay within our existing framework by modeling the evasion of taxes on labor income in the same way as before, including the risk-neutrality of the consumer with respect to any risks associated with tax evasion. Thus the government's optimization problem is amended in only two ways to account for this new source of tax evasion. First, the unit tax rate on labor income in the government budget constraint becomes $b^{e} w(r)$, where $b^{e}$ is the effective ad valorem tax rate on labor income. Secondly, the (expected) after-tax wage is now:

$$
\omega^{e}=w(r)\left[1-b^{e}-h\right]
$$

where $h$ is evasion costs per unit of labor income (now assumed not to be tax deductible). ${ }^{13}$ The consumer chooses evasion activities that minimize $b^{e}+h$, and the solution to this problem defines both $b^{e}$ and $h$ as functions of the "statutory" tax rate on labor income, denoted $b$.

With these changes, we first isolate the impact of the evasion of labor taxation by considering the case where there is no evasion of taxes on domestic capital income.

Proposition 2. Assume that taxes on labor income are evaded, with $h>0$ and $d h / d b \geq 0$, but there is no evasion of taxes on domestic capital income. Under the optimal tax system, $T^{e}<t$.

Proof. At the optimum, any small perturbation in the tax system has a zero first-order impact on the Lagrangian for the government's problem. Consider one such perturbation consisting of a unit rise in $t$, which changes the before-tax wage by $w^{\prime}(r)(\partial r / \partial t)$, and a reduction in $b$ by an amount denoted $d b / d t<0$, which keeps the after-tax wage unchanged. As a result, there is no change in the objective function for problem (P.3), but the government budget constraint does change. To see how, note from (17) that the

\footnotetext{
${ }^{13}$ The assumption that $h$ is not tax deductible seems most reasonable in the case of labor income, but the tax deductibility would be more likely if we assumed that firms evade labor income taxes on behalf of workers (e.g. untaxed fringe benefits with various forms of legality, or labor compensation reported as tax payments for capital). Our results here do not depend on whether deductibility is assumed.
} 
unit tax rate on labor income satisfies, $b^{e} w(r)=w(r)(1-h)-\omega^{e}$. Hence the government budget constraint given by (12) may be rewritten:

$$
\begin{aligned}
& E \leq\left\{\left(w(r)(1-h)-\omega^{e}\right)+[r-R(1-G)] k(r)\right\} L\left(q, \omega^{e}, M\right) \\
& +T^{e} R(1-G)\left[I-c^{1}\left(q, \omega^{e}, M\right)\right]
\end{aligned}
$$

where $r$ is again determined by $T$ and $t$, and we are using the assumption that $g=0$. For an optimal tax system, our small perturbation must have a zero first-order impact on this constraint, implying the following condition:

$$
[r-R(1-G)] k^{\prime}(r)\left(\frac{\partial r}{\partial t}\right)-\left\{w^{\prime}(r)\left(\frac{\partial r}{\partial t}\right) h+w(r)\left(\frac{d h}{d b}\right)\left(\frac{d b}{d t}\right)\right\}=0
$$

where the equality, $w^{\prime}(r)=-k$, is used to cancel terms. We know that $k^{\prime}(r)(\partial r / \partial t)<0$, $(d h / d b)(d b / d t) \leq 0$, and $w^{\prime}(r)(\partial r / \partial t)<0$. Thus the expression in the curly brackets is negative, implying that $r-R(1-G)>0$. It follows from the arbitrage condition, (6), that $t>T^{e}$.Q.E.D.

Thus the government responds to evasion in the labor market by setting a relatively high tax rate on domestic capital income. The basic explanation is that a rise in $t$ now lowers evasion costs in two ways. First, it reduces the amount of labor income that is subject to tax evasion by causing $w(r)$ to fall. Secondly, the fall in $b$ needed to maintain a constant after-tax wage causes evasion activities to fall (i.e. $h$ falls). These two effects are represented by the terms in the curly brackets in (19). At the optimum, it is worthwhile to obtain these reduced evasion costs by raising $t$ above $T^{e}$, although this causes capital exports to be inefficiently large.

Perhaps the most empirically relevant assumption is that opportunities to evade taxes on capital income are more widespread compared with labor income, so that the forces that raise $T^{e}$ above $t^{e}$ dominate. In fact, it is possible to show that this difference in taxes must prevail if we make the empirically reasonable assumption that labor income is effectively taxed more than domestic capital income (i.e. $b^{e}>t^{e}$ ), and we represent the greater importance of capital tax evasion by the following assumptions at the optimum: $g>h, d g / d t>d h / d b$, and $\partial t^{e} / \partial t<\partial b^{e} / \partial b^{14}$ The first two inequalities say that the total and marginal evasion costs incurred on each unit of income are greater in the capital sector, and the third inequality provides a sense in which more evasion successfully occurs at the margin in the capital sector.

\footnotetext{
${ }^{14}$ These results are obtained by using the equality $b^{e} w(r)=w(r)(1-h)-\omega^{e}$, to compute $[d b / d t] w=w^{\prime}(r)[\partial r / \partial t]\left[1-h-b^{e}\right] /\left[\partial b^{e} / \partial b\right]$ in $(19)$, where $\omega^{e}$ is held fixed by assumption and we use the envelope theorem to eliminate the cost change $d h / d b$. A similar use of the envelope theorem gives $\partial r / \partial t=\left[\partial t^{e} / \partial t\right] r /\left[1-t^{e}\right]$. Substituting these derivatives into (19) and (13) then proves the claim. Note that the assumption that $b^{e}>t^{e}$ is a statement about effective marginal tax rates, which can hold even if the corresponding statutory rates differ strongly in the opposite direction.
} 


\section{Other Extensions}

We now discuss some additional extensions of the model. Taken as a whole, these extensions provide further support for relatively high taxes on foreign-source income.

We have worked with a class of models in which the effective tax rate on capital income depends only on the tax rate and evasion costs: $T^{e}=T^{e}(T, G)$. A possible alternative would be to assume that $T^{e}$ depends on the amount of investment abroad: $T^{e}$ $=T^{e}(T, G, B)$. In this case, a reduction in the tax rate on capital income at home can have general equilibrium effects on evasion cost $G$ through the resulting reduction in capital exports. Proposition 1 must therefore be modified, depending on the relation between $T^{e}$ and $B$. Suppose, for example, that we drop the constant-returns assumption at the firm level, and model an endogenous determination of the number of domestic firms with operations abroad. One could envision the following process. As the tax rate $t$ is reduced, $B$ declines and there is an accompanying drop in the number of domestic firms operating abroad. Given the budget available for catching tax cheats, more resources can now be devoted to detecting tax evasion in each of these firms. As a result, each firm is induced to lower its $G$. (In the model presented in the Appendix, for example, $G$ is a declining function of the probability of an audit.) Thus, a reduction in $t$ leads to a reduction in wasteful evasion costs abroad, and this consideration reinforces the tendency for domestic capital income to be taxed relatively lightly.

This argument follows the previous analysis by treating the determination of tax rates as a suboptimization problem, for which the government's expenditures devoted to detecting tax evaders are exogenous. Thus, our conclusions are meant to hold whether or not these detection activities are optimal. For the model presented in the Appendix, it is straightforward to endogenize the audit probability, but the investigation of models with superior, but more complicated, audit policies in an optimal tax model would be useful.

Another extension would be to enable the consumer to directly purchase a portfolio of foreign assets, which are taxed at a separate personal rate, $T^{P}$ and to allow the consumer to evade this tax by under-reporting the earnings on these assets. This tax evasion can be modeled as before by introducing another evasion cost function, $G^{P}\left(T^{P}\right)$. Unlike the previous forms of tax evasion, the consumer now bears the burden associated with the risks of random audits of the foreign portfolio. However, it is easily seen that adding a second source of foreign-source income does nothing to alter the argument behind Proposition 1 and, hence, is irrelevant for the optimal difference between $T^{e}$ and $t^{e}$. A new issue is how the tax rates on the two types of foreign income should differ. There is no general answer, since the evasion of taxes on portfolio investment means that we are effectively taxing a risky asset, and the optimal levels of such taxes depend on attitudes towards risk. Examples can be presented in which the expected value of $T^{P}$ exceeds $T^{e}$, again demonstrating that taxes on foreign-source income can be relatively high. ${ }^{15}$

\footnotetext{
${ }^{15}$ The basic idea behind these examples is that a rise in $T^{P}$ reduces the equilibrium fraction of savings that is subject to tax evasion risk, where it must earn a higher expected return to compensate for the risk. Thus, more savings are required to maintain a given expected value of future consumption, all else equal. For this reason, a rise in $T^{P}$ can encourage savings, while a rise in $T$ has the opposite effect. This consideration tends to raise $T^{P e}$ above $T^{e}$. Differences in evasion technologies can have offsetting effects, however.
} 
Consider next taxes levied by foreign governments, and let us allow for the common practice of crediting these taxes against domestic tax liabilities. Small values of $T$ raise no revenue and have no incentive effects, since the burden of the tax is eliminated by the tax credit. Thus the government will raise $T$ beyond this range, and there will be no change in the arbitrage condition, given by (6): $T^{e}$ continues to determine the total tax burden that investors face on foreign-source income. However, for each unit of capital invested abroad, the home government receives only $R(1-G)\left(T^{e}-S\right)$, where $S$ is the foreign tax rate. ${ }^{16}$ As a result, the social value that the home government places on investment abroad is reduced to $R(1-G)(1-S)$, and efficiency in capital exports requires that this return equal $r$ in the absence of domestic tax evasion. In other words, $R(1-G)$ must exceed $r$ to compensate for foreign taxes, and this is only possible in equilibrium if $T^{e}$ is greater than $t$.

Thus, the only change in Proposition 1 is the replacement of the equality, $T^{e}=t$, with the inequality, $T^{e}>t$, when there is no domestic tax evasion, while $T^{e}$ continues to exceed $t^{e}$ with domestic tax evasion. We may conclude that foreign tax credits reinforce the case for relatively high effective tax rates abroad.

Finally, an important issue is the extent to which foreign governments cooperate in collecting such taxes, including sharing information on taxpayers. Our working assumption that it is significantly easier to evade taxes on income earned abroad reflects the belief that such cooperation is difficult to elicit, but our introduction has noted that information-sharing arrangements do exist and are now an active research topic (e.g. Keen and Ligthart, 2006). It would be useful to extend our current model to explicitly allow information-sharing and domestic enforcement policies to substitute for each other to some extent.

\section{Concluding Remarks}

We have shown that with unfettered capital mobility, foreign tax evasion does not lower the effective rate at which foreign-source income should be taxed relative to domestic capital income. Instead, severe evasion problems abroad are translated into lower capital taxes both at home and abroad. In fact, Proposition 1 shows that foreignsource income should be taxed at the higher effective rate when tax evasion exists at home.

Given the surprising nature of these results, we have subjected them to considerable scrutiny by extending the basic model in a number of different directions. They seem to hold up rather well, but we caution that many issues remain to be explored. We have only briefly touched on uncertainty, and we have ignored the game-theoretic

\footnotetext{
${ }^{16}$ We assume here that the home government's tax policy influences only those evasion activities directed towards lowering the burden of home's tax on foreign-source income (i.e. $S$ does not depend on $T$ ). An alternative view is that evasion activities produce a "joint product": lower tax liabilities to both home and foreign governments. In an intriguing paper, Scharf (2001) employs this assumption to demonstrate that countries might have an incentive to implement a tax credit system as a means of inducing firms to reduce their evasion activities. Her argument is based on the idea that a firm does not benefit from a lower tax liability to foreign governments, if the home government is providing a tax credit for this liability.
} 
considerations that arise when capital movements occur between a small number of countries, and when markets are imperfectly competitive. However, our analysis suggests that arguments against taxing foreign-source income simply because it is "too hard to tax" are far less self-evident than one might believe. 


\section{Appendix}

\section{A Model of Tax Evasion}

By amending Cremer and Gahvari's (1993) model of optimal commodity taxation with tax evasion, we shall obtain a model with the essential properties of the "reducedform" model presented in the text. They assume that a firm evades taxes by reporting only a proportion of the sales of the good it produces. The tax administration makes a costless "cursory examination" of these sales, and this examination reveals the actual sales unless the firm spends resources to conceal sales. The cost of this concealment is a convex function of the proportion of sales that are concealed. The tax administration also audits firms at random. These costly audits reveal actual sales.

For our analysis, under-reporting of capital income is the problem. Consider the evasion of taxes on foreign-source income. (Domestic tax evasion is modeled in the same way.) The cost of concealing each dollar of taxable income is a function of the fraction of taxable income that goes unreported: $H(A)$, where $A$ denotes this fraction and we assume that $H(0)=H^{\prime}(0)=0$ and, for $A>0, H^{\prime}(A)>0$ and $H^{\prime \prime}(A) \geq 0$. These properties ensure that there is a solution to a firm's optimal evasion problem, and that this solution involves some evasion at any positive $T$. The cost of tax evasion per dollar of taxable income is, $\mathrm{G}^{*}(A)=A H(A)$, and the properties of $H(A)$ imply that $G^{*}(A)$ has positive first and second derivatives.

The firm is audited with probability $\pi$, in which case it is caught evading taxes and assessed a penalty that effectively raises its tax rate on unreported income to $P T$, where $P-1$ is the penalty rate. The firm's expected tax rate on a dollar of foreign-source income is then:

$$
T^{e}=[(1-A)+A \pi P] T
$$

We assume that $\pi P<1$, since tax evasion would otherwise increase $T^{e}$, thereby eliminating any incentive to evade taxes. By inverting $G^{*}(A)$ to get $A=A(G)$ and substituting this function into (A.1), we obtain the function $T^{e}(T, G)$ in the text, with $\partial T^{e} / \partial T>0$ and $\partial T^{e} / \partial G<0$.

The function $G(T)$ in the text is derived as follows. The firm earns a return of $R(1-G)\left(1-T^{e}\right)$ on a unit of investment abroad. Hence it chooses $A$ to maximize this return, and the first-order condition is:

$$
G^{* \prime}(A)\left(1-T^{e}\right)=\left[1-G^{*}(A)\right](1-\pi P) T
$$

Since the left side rises with $A$ and the right side falls with $A$, this condition uniquely determines $A$ as a function of $T$. We therefore have $G(T)=G^{*}(A(T))$, and $T^{e}(T)=T^{e}(T, G(T))$. Note in particular that $\partial T^{e} / \partial T>0$, where the partial derivative indicates that $G$ is held fixed. By the envelope theorem,

$$
\frac{d\left[R(1-G)\left(1-T^{e}\right)\right]}{d T}=-R(1-G) \frac{\partial T^{e}}{\partial T}<0,
$$


where the total derivative indicates the $G$ changes according to the relation $G(T)$. Both of these properties are used in the text.

Derivation of Equation (14). The Lagrangian for problem (P.3) is:

$$
\begin{aligned}
& L=v(q, \omega, M)+\lambda\{[(w(r)-\omega)+[r(1-g)-R(1-G)] k(r)] L(q, \omega, M) \\
& \left.+T^{e} R(1-G)\left[I-c^{1}(q, \omega, M)\right]-E\right\}
\end{aligned}
$$

where $\lambda$ is a Lagrange multiplier. To obtain the first-order condition for $T$, differentiate this Lagrangian with respect to $T$, using the relation between $M$ and $T$ given by (2) and (9):

$$
\begin{aligned}
& {\left[v_{q}+v_{M} I+\lambda\left(-T^{e} R c^{1}+\beta L_{q}\right)\right] \frac{d\left[(1-G)\left(1-T^{e}\right)\right]}{d T}} \\
& +\lambda\left(I-C^{1}\right) \frac{d\left[T^{e}(1-G)\right]}{d T}+\lambda K \frac{d G}{d T}=0
\end{aligned}
$$

where $K=k L$ and:

$$
\beta=[w(r)-\omega]+[r(1-g)-R(1-G)] k(r)
$$

or, by the arbitrage condition given by (6) and the relation, $k=-w^{\prime}(r)$,

$$
\beta=[w(r)-\omega]-w^{\prime}(r)\left[t^{e} r(1-g)-T^{e} R(1-G)\right]
$$

which is (15) in the text. Divide (A.5) by $d\left[(1-G)\left(1-T^{e}\right)\right] / d T$, apply Roy's Identity, and rearrange the result to obtain:

$$
\left[\lambda-v_{M}\right]\left(I-C^{1}\right)=\lambda\left[\beta L_{q}-T^{e} R c_{q}^{1}-B \frac{d G / d T}{d\left[(1-G)\left(1-T^{e}\right)\right] / d T}\right]
$$

An application of Slutsky's equation, along with use of (A.3), then yields:

$$
[\lambda-\delta]\left(I-C^{1}\right)=\lambda\left[\beta L_{q}^{s}-T^{e} R C^{1 s}{ }_{q}+B(1-G)^{-1} \frac{d G / d T}{\partial T^{e} / \partial T}\right]
$$

where $\delta$ is the social marginal utility of income, as defined:

$$
\delta=v_{M}+\lambda\left[\operatorname{te}^{e} r\left(-c^{1}{ }_{M}\right)+\beta L_{M}\right]
$$

By applying the symmetry property, $L_{q}^{s}=-C_{\omega}^{1 s}$ we may rewrite (A.9) as follows:

$$
\frac{\lambda-\delta}{\lambda}-\frac{B}{I-C^{1}}(1-G)^{-1} \frac{d G / d T}{\partial T^{e} / \partial T}=\frac{\beta\left(-C^{1 s}{ }_{\omega}\right)+T^{e} R\left(-C^{1 s}\right)}{I-C^{1}}
$$

Similar manipulations of the first-order condition for $\omega$ yield:

$$
\frac{\lambda-\delta}{\lambda}=\frac{\beta L_{\omega}^{s}+T^{e} R L_{q}^{s}}{L}
$$

Combining (A.11) and (A.12) yields (14) in the text. 


\section{References}

Auerbach, A., M.P. Devereux, and H. Simpson, 2007, "Taxing Corporate Income”, Working Paper 07/05, Oxford University Centre for Business Taxation, Said Business School, Oxford University.

Blumenthal, M. and J. B. Slemrod, 1995, "The Compliance Cost of Taxing ForeignSource Income: Its Magnitude, Determinants, and Policy Implications", International Tax and Public Finance 2, 37-54.

Bucovetsky, S. and J. D. Wilson, 1991, "Tax Competition with Two Tax Instruments", Regional Science and Urban Economics 21,333-350.

Cremer, H. and F. Gahvari, 1993, "Tax Evasion and Optimal Commodity Taxation”, Journal of Public Economics 50, 261-276.

Gresik, T., 2001, "The Taxing Task of Taxing Transnationals", Journal of Economic Literature 39, 800-838.

Davies, R. B., 2004, “Tax Treaties and Foreign Direct Investment: Potential versus Performance", International Tax and Public Finance 11, 775-802.

Diamond, P. A. and J. A. Mirrlees, 1971, “Optimal Taxation and Public Production", American Economic Review 61, 8-27 and 261-278.

Gordon, R. H., 1986, "Taxation of Investment and Savings in a World Economy", American Economic Review 76, 1086-1102.

Gordon, R.H., and J. K. MacKie-Mason, 1995, "Why is There Corporate Taxation in a Small Open Economy? The Role of Transfer Pricing and Income Shifting", in M. Feldstein, J. Hines Jr., and R. Hubbard (eds.), The Effects of Taxation on Multinational Corporations (Chicago: University of Chicago Press), 67-91.

Hines, J. A., 2007, "Corporate Taxation and International Competition”, in: A. J. Auerbach, J. R. Hines and J. Slemrod, eds., Taxing Corporate Income in the 21st Century, (Cambridge: Cambridge University Press), 268-295.

Keen, M., and J. E. Ligthart, 2006, "Information sharing and international taxation: A primer", International Tax and Public Finance 13, 81-110.

Scharf, K. A., 2001, "Can International Capital Tax Evasion Explain the Foreign Tax Credit Puzzle?", Canadian Journal of Economics 34, 465-480.

Slemrod, J. and S. Yitzhaki, 2002, "Tax Avoidance, Evasion, and Administration”, in: A. Auerbach and M. Feldstein, eds., Handbook of Public Economics, (Amsterdam, London, and New York: Elsevier).

Slemrod, J. and J. D. Wilson, 2007, "Tax Competition with Parasitic Tax Havens", unpublished mimeo., Michigan State University.

Smart and Qing, 2006, "In Praise of Tax Havens: International Tax Planning and Foreign Direct Investment", unpublished mimeo., University of Toronto.

Wilson, J. D., Comment on "Corporate Taxation and International Competition", in: A.J. Auerbach, J. R. Hines and J. Slemrod, eds., Taxing Corporate Income in the 21st Century, (Cambridge: Cambridge University Press), 300-306. 